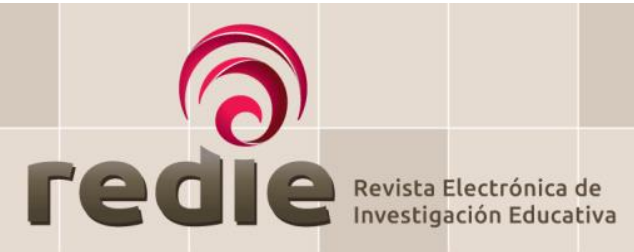

ISSN: 1607-4041

https://redie.uabc.mx

Vol. 23, 2021/e22

\title{
Itinerario didáctico multidisciplinar en Madrid: validación con maestros en formación
}

\author{
A Multidisciplinary Educational Itinerary in Madrid: \\ Validation with Trainee Teachers
}

Carlos Martínez-Hernández (1) https://orcid.org/0000-0002-6526-6905

Claudia Yuvero (1) https://orcid.org/0000-0001-5731-333X

Franciso Javier Robles Moral (2) https://orcid.org/0000-0003-0987-8103

(1) Universidad Complutense de Madrid

(2) Universidad de Murcia

(Recibido: 15 de octubre de 2019; Aceptado para su publicación: 8 de enero de 2020)

Cómo citar: Martínez-Hernández, C., Yuvero, C. y Robles, F. J. (2021). Itinerario didáctico multidisciplinario en Madrid: validación con maestros en formación. Revista Electrónica de Investigación Educativa, 23, e22, 1-18. https://doi.ora/10.24320/redie.2021.23.e22.3483

\section{Resumen}

Este trabajo tiene como objetivo el diseño y validación de un itinerario didáctico en Madrid con estudiantes de un Grado en Educación Primaria, conformado por visitas y actividades relacionadas con los currículos de Ciencias Sociales y Naturales y, en vinculación, las asignaturas universitarias relacionadas con sus didácticas. La validación se establece con un análisis de datos de enfoque mixto mediante un cuestionario al alumnado participante y una puesta en común de aprendizajes. Entre los resultados destacan el alto porcentaje de nuevos conocimientos multidisciplinares adquiridos, la elevada valoración del conjunto del itinerario y sus partes y la eficacia del ejercicio de geografía urbana para comprender la turistificación de los centros urbanos. Se concluye que los itinerarios didácticos como el de esta experiencia pueden contribuir a mejorar sustancialmente la formación docente y permitir una mayor transferencia a la etapa primaria, por lo que su réplica -con ciertas correcciones detalladas- es aconsejable.

Palabras clave: estrategia de enseñanza, visita educativa, formación de docentes, enseñanza primaria

\begin{abstract}
The objective of this study is to design and validate an educational itinerary in Madrid with students from an undergraduate degree in primary education. The educational itinerary included field trips and activities associated with social and natural sciences curricula and was undertaken in connection with university courses in teaching methods for these subject areas. It was validated with mixed methods data analysis from a questionnaire administered to participating students and a round table during which students pooled what they had learned. Findings include high levels of acquisition of new multidisciplinary knowledge and a highly favorable view of the itinerary, its components, and the effectiveness of the urban geography activity in understanding the touristification of cities. We conclude that educational itineraries like the one used in this research can help to substantially improve teacher training and facilitate transfer to primary education, so recreating this exercise - with a few adjustments as detailed - is advised.
\end{abstract}

Keywords: teaching strategies, educational visits, teacher education, elementary education 


\section{Introducción}

Un itinerario didáctico, en su acepción de salida didáctica, de campo o escolar, consiste en una actividad grupal con fines didácticos que tiene lugar fuera del aula, en un espacio geográfico que es fuente de conocimiento y al que accede el alumnado a través de una experiencia vivencial de motivación y desarrollo personal. Álvarez et al. (2016) caracterizan las salidas didácticas como la oportunidad de explorar, descubrir y redescubrir una realidad cercana o lejana para los estudiantes, siendo un proceso donde la observación, la descripción y la explicación in situ juegan un papel esencial. Aguilera (2018) encuentra tres coincidencias en todas las definiciones: se trata de una actividad que tiene lugar fuera del aula, tiene un fin educativo y genera experiencia en el alumnado. Según Crespo et al. (2018):

Este tipo de actividades facilitan al alumnado la comprensión holística del medio en el que se desenvuelve, proporcionan al profesorado un instrumento alternativo para trabajar los aspectos relacionados con el espacio y favorecen el desarrollo de la comprensión multicausal de los procesos, factores y elementos espaciales (p. 126)

El Manifiesto por el Aprendizaje Fuera del Aula (Council for Learning Outside the Classroom, 2006) destaca que cualquier joven debería experimentar el mundo que hay más allá del aula, como una parte esencial del aprendizaje y del desarrollo personal. Además, las salidas didácticas influyen muy positivamente en los aspectos emocionales, conceptuales y procedimentales, dando como resultado el desarrollo de la observación, la indagación y la discusión, elementos implicados en la motivación del alumnado (del Toro y Morcillo, 2011).

Las salidas o itinerarios didácticos no son, en sí mismos, un recurso innovador; ya Sorrentino y Bell (1970) apuntaban los propósitos por los que se podía usar este instrumento didáctico: propiciar una experiencia, estimular el interés y la motivación, atribuir relevancia al aprendizaje, desarrollar habilidades de observación y percepción y favorecer el desarrollo personal y social. A lo largo del siglo XX autores como John Dewey, Célestin Freinet o Maria Montessori, por mencionar algunos, entendieron la necesidad de salir del aula (Aguilera, 2018). Esta idea hunde sus raíces a finales del siglo XIX en la concepción pedagógica del excursionismo geográfico desarrollado en España por la Institución Libre de Enseñanza, a través de las Escuelas Normales y la Real Sociedad Geográfica (Crespo et al., 2018).

Sin embargo, a pesar del recorrido histórico de estas consideraciones, Pedrinaci (2012) señala que el número actual de salidas didácticas es relativamente bajo, lo que produce en el estudiante la sensación de novedad e, incluso, que los docentes perciban, de manera errónea, que son elementos pedagógicos innovadores. Rebelo et al. (2011) atribuyen este reducido número principalmente a la cantidad de alumnos por aula, la dedicación y tiempo extra, los aspectos económicos y administrativos, la escasez de materiales didácticos y la consabida responsabilidad civil que conllevan este tipo de acciones.

En el ámbito de la formación del profesorado, Costillo et al. (2014) señalan que las salidas didácticas no sólo benefician el plano afectivo, sino también el cognitivo y las competencias transversales, aumentando la calidad de la educación. Por ello, si los futuros profesores las realizan dentro de su formación podrán ver acrecentado su aprendizaje del medio natural, social y cultural y, debido a un efecto cascada, sus futuros alumnos también verán incrementados sus conocimientos.

Estas consideraciones ganan mayor importancia cuando los aprendizajes que se pretenden son epistemológicamente complejos, ya que una aproximación empírica a los mismos, mediante una metodología activa, los vuelve más atractivos y asequibles (Delgado y de Justo, 2018). Solbes (2011) señala que el uso de las salidas didácticas para la enseñanza de ciencias mejora la percepción de los estudiantes, $a$ priori poco atractiva y desconectada de la vida y sociedad actual, lo cual puede deberse, según Cañas y Martín-Díaz (2010), a la densidad de las programaciones didácticas, el lenguaje propio, la necesidad de conocimientos previos, y la falta de empatía entre el docente y el alumno.

Al amparo de las consideraciones mencionadas, el objetivo general de este trabajo es el diseño y validación de un itinerario didáctico en Madrid con estudiantes de Grado en Educación Primaria de la Universidad de 
Murcia (sureste de España), conformado por visitas y actividades relacionadas con los currículos de Ciencias Sociales y de Ciencias de la Naturaleza y, en vinculación, las asignaturas universitarias relacionadas con sus didácticas. Los objetivos específicos son demostrar los resultados de aprendizaje (didácticos y de desarrollo personal), la capacidad de transferencia hacia la educación primaria y la eficacia de la multidisciplinariedad entre las ciencias sociales y naturales.

A nivel curricular, tal como establece la memoria verificada del Título (Agencia Nacional de Evaluación de la Calidad y Acreditación [ANECA], 2018), esta actividad persigue el desarrollo de las siguientes competencias específicas de titulación:

(CE1) Conocer las áreas curriculares de la Educación Primaria (...) y el cuerpo de conocimientos didácticos en torno a los procedimientos de enseñanza y aprendizaje respectivos.

(CE2) Diseñar, planificar y evaluar procesos de enseñanza y aprendizaje, tanto individualmente como en colaboración (...).

(CE4) Diseñar y regular espacios de aprendizaje en contextos de diversidad y que atiendan a la igualdad de género, a la equidad y al respeto de los derechos humanos que conformen los valores de la formación ciudadana.

(CE8) Mantener una relación crítica y autónoma respecto de los saberes, los valores y las instituciones sociales públicas y privadas.

De manera complementaria, el itinerario didáctico contribuye también a la adquisición de las siguientes competencias generales (transversales para todos los grados universitarios):

(CG5) Ser capaz de proyectar los conocimientos, habilidades y destrezas adquiridos para promover una sociedad basada en los valores de la libertad, la justicia, la igualdad y el pluralismo.

(CG6) Capacidad de trabajar en equipo y para relacionarse con otras personas del mismo o distinto ámbito profesional.

(CG7) Desarrollar habilidades de iniciación a la investigación.

La transferencia en la etapa educativa primaria, en función de las visitas y actividades que más adelante se detallan, se concreta de forma multidisciplinar en las áreas de Ciencias Sociales y Ciencias de la Naturaleza (Real Decreto 126, 2014). En la primera, ocurre a través de todos los bloques de contenidos, en cuanto al tratamiento de fuentes, convivencia y fomento de técnicas de entrevista (Bloque 1: Contenidos comunes); manejo cartográfico y orientación (Bloque 2: El medio en que vivimos); organización política y territorial, jurisdicción, geografía urbana, turismo y movilidad (Bloque 3: Vivir en sociedad); e historia, historiografía, historia del arte y valorización patrimonial (Bloque 4: Las huellas del tiempo). En Ciencias de la Naturaleza los contenidos quedan englobados de forma genérica en el Bloque 1 de Iniciación a la investigación científica (Aproximación experimental a algunas cuestiones, iniciación a la actividad científica, vocabulario técnico del área, etc.), en el Bloque 3 de los seres vivos (los seres vivos: Características, clasificación y tipos; hábitos de respeto y cuidados hacia los seres vivos, interés por la observación y el estudio riguroso de todos los seres vivos, uso de medios tecnológicos para el estudio de los seres vivos, etc.), e incluso dentro del Bloque 5 de Tecnología, objetos y máquinas, con contenidos como La ciencia: presente y futuro de la sociedad.

\section{Método}

El itinerario didáctico se diseñó teniendo en cuenta una elección justificada de la ciudad de destino y de las actividades y visitas planificadas, en función de criterios pedagógicos, didácticos y competenciales. Para validarlo, bajo una concepción constructivista del aprendizaje, el itinerario se llevó a la práctica con maestros en formación, a través de una experiencia vivencial en la que los participantes llevan a cabo en 
primera persona una actividad que pueden reproducir, adaptada, con su futuro alumnado. Sobre esto se estableció un análisis de datos de enfoque mixto (cuantitativo-cualitativo) mediante un cuestionario al alumnado participante y una puesta en común de aprendizajes.

Participantes. La puesta en práctica del itinerario se llevó a cabo con alumnado del Grado en Educación Primaria de la Facultad de Educación de la Universidad de Murcia, de su centro adscrito de Cartagena, concretamente 14 estudiantes matriculados en las asignaturas de 2o. curso: Ciencias Sociales y su didáctica, y Didáctica de ciencias experimentales ( $6+6$ créditos) y, de 30.: Metodología didáctica para la enseñanza de las Ciencias Sociales y Enseñanza y aprendizaje del medio natural II (6 +6 créditos). Conforman el 100\% de los participantes en el viaje de estudios del centro, que tuvo lugar en abril de 2018, una logística que se aprovechó para llevar a cabo el itinerario didáctico en un viaje interregional de $450 \mathrm{~km}$.

Elección del destino. Madrid, como metrópoli central y capital del país, aglutina servicios y organismos de toda índole y presenta envidiables prestaciones didácticas, culturales e institucionales, que facilitan el aprovechamiento pedagógico que fundamenta el itinerario. Asimismo, su distancia respecto a Cartagena, lejos para una ida y vuelta en el día pero lo suficientemente cerca para ser asumible sin excesivos costes económicos y logísticos de transporte y alojamiento, permite cubrir en el alumnado su expectativa de disfrutar de un viaje de estudios, por la propia experiencia del viaje en sí, generadora de compañerismo, diversión y espíritu universitario, y sin renunciar, gracias a la eficacia didáctica del itinerario diseñado, a la adquisición de competencias y nuevos contenidos curriculares. Como afirma Benejam (2003), las salidas didácticas son un "medio para promover la convivencia, el conocimiento entre alumnos, entre alumnos y profesores, construir la idea de grupo y propiciar actitudes de participación y colaboración" (p. 7).

Justificación de las visitas/actividades. Partiendo de un alojamiento hostelero relativamente céntrico de asumible coste económico, se diseñó un itinerario por la ciudad de Madrid que, combinando la disponibilidad de las reservas cuando eran necesarias y la optimización de la movilidad para cuadrar horarios, consistió en la visita a siete lugares y la realización de una actividad de análisis de geografía urbana focalizada en dos barrios céntricos (Figura 1).

Figura 1. Cartografía del itinerario didáctico en Madrid: visitas/actividades realizadas y calendarización

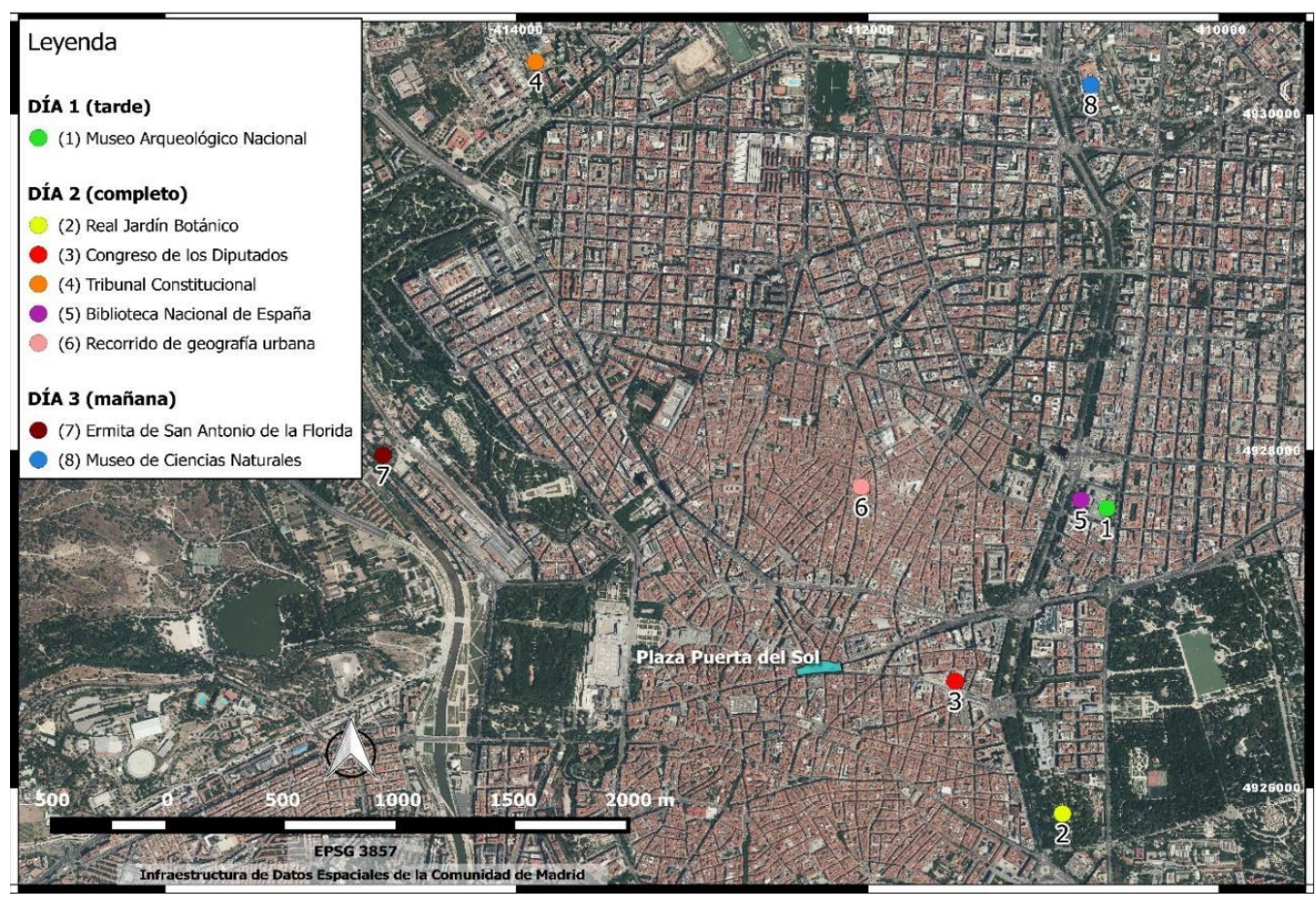


Los criterios didácticos y competenciales de las paradas de este itinerario, siempre tendentes al tratamiento multidisciplinar de las Ciencias Sociales y Experimentales/Naturales -en sí mismas y entre síse han sintetizado en las figuras 2 y 3. Como justificación pedagógica general de cada actividad se anotan las siguientes consideraciones:

1) Museo Arqueológico Nacional: el museo permite un recorrido exhaustivo por toda la historia de la humanidad, por etapas y civilizaciones. Los alumnos pueden aprender, consolidar y mejorar en una sola visita, de forma significativa y eficaz, lo que los currículos educativos organizan en años de estudio, no sólo en contenido sino en expresión didáctica.

2) Real Jardín Botánico: en pleno centro, este lugar alberga infinitud de especies vegetales de todo el mundo, en lo que podría considerarse el mejor museo de flora de España. Los alumnos pueden conocer en primera persona, con motivación y de forma significativa, la vegetación (clave en las clases de Ciencias Naturales) que han aprendido de forma teórica.

3) Congreso de los Diputados: uno de los contenidos en Ciencias Sociales más difíciles de entender quizá sea la gobernanza, reconociendo la labor de cada institución en función de la escala geográfica. No es un tema baladí puesto que, sin comprender este complejo funcionamiento democrático, un maestro no es capaz de explicarlo significativamente a sus alumnos en Primaria, y estos crecerán sin comprender cuál es el importantísimo valor de la democracia, cuáles son sus fundamentos y cómo debemos ser críticos y cívicos para asegurarla y desarrollarla en un ambiente de tolerancia cero hacia la corrupción.

4) Tribunal Constitucional: la visita, con guía concertada, permite al alumno comprender cómo vela el Estado por el cumplimiento de la separación de poderes a través de este máximo órgano de vigilancia constitucional -muy mediático en este momento, por la actualidad política en el ámbito institucional, debido al desafío soberanista catalán.

5) Biblioteca Nacional de España: en clase se da importancia a las fuentes primarias para "construir" historia, de manera que esto les sirva a los discentes para comprender cómo se configuran los discursos históricos académicos y que sean capaces de interpretarlos de forma crítica. Aquí podemos conocer cómo se gestionan las obras originales, ver algunos ejemplos en primera persona y, en general, descubrir cómo se estructura y funciona una biblioteca de este nivel.

6) Recorrido de geografía urbana: el centro de Madrid, como otras metrópolis, se está viendo afectado por un intenso proceso de turistificación que genera conflictos en el uso del espacio público entre los residentes tradicionales y los turistas, llegando a veces a situaciones de gentrificación (Sequera y Janoshka, 2015).

Pedir a los alumnos un análisis de geografía urbana en zonas representativas puede hacerles comprender significativamente este fenómeno, que didácticamente se encuentra ausente en el Grado universitario aunque es de plena actualidad -e incluso forma parte indirecta de los contenidos curriculares de Educación Primaria en torno a los sectores económicos.

Del mismo modo, se desarrollan procedimientos básicos de geografía urbana, así como contenidos actitudinales como el respeto en la interacción social y la valorización de los centros urbanos. Madrid ofrece una gran potencialidad didáctica en torno al trabajo de campo, clave en las Ciencias Sociales.

7) Ermita de San Antonio de la Florida: de estilo neoclásico, la ermita alberga frescos de Goya y su tumba. Conocerla permite desarrollar significativamente algunos de los contenidos de historia del arte que forman parte tanto del currículum de Primaria como del Grado en Educación Primaria. La preferencia por esta visita radica en su accesibilidad, su gratuidad y por no estar turísticamente masificada.

8) Museo Nacional de Ciencias Naturales: su visita, que es una clase ambiental magistral, permite conocer la historia biogeológica del planeta, de una forma didáctica y lúdica, en un recorrido cautivador que motiva y conduce al aprendizaje global de las Ciencias Naturales facilitando una futura trasposición didáctica. 
Figura 2. Criterios del itinerario diseñado: competencias

\begin{tabular}{|c|c|}
\hline Competencias de materia (Didáctica de las CC.SS y Didáctica de las CC.EE y NN) & Actividades \\
\hline Comprender los principios básicos de las ciencias sociales & 1 y 3 \\
\hline Conocer el currículo escolar de las ciencias sociales & $1,3,4,5,6 y 7$ \\
\hline $\begin{array}{l}\text { Fomentar la educación democrática de la ciudadanía y la práctica del pensamiento } \\
\text { social crítico }\end{array}$ & $1,3,4,5,6$ y 7 \\
\hline $\begin{array}{l}\text { Valorar la relevancia de las instituciones públicas y privadas para la convivencia } \\
\text { pacífica entre los pueblos }\end{array}$ & $1,2,3,4,5,7$ \\
\hline Conocer el hecho religioso a lo largo de la historia y su relación con la cultura & 1 y 7 \\
\hline $\begin{array}{l}\text { Desarrollar y evaluar contenidos del currículo mediante recursos didácticos } \\
\text { apropiados y promover las competencias correspondientes en los estudiantes }\end{array}$ & $\begin{array}{l}1,2,3,4,5,6 \\
\quad 7 \text { y } 8\end{array}$ \\
\hline $\begin{array}{l}\text { Conocer la metodología científica y promover el pensamiento crítico, la observación y } \\
\text { la experimentación }\end{array}$ & $1,2,6$ y 8 \\
\hline $\begin{array}{l}\text { Comprender los principios básicos y las leyes fundamentales de las ciencias } \\
\text { experimentales (Física, Química, Biología y Geología) }\end{array}$ & 2 y 8 \\
\hline Conocer el currículo escolar de las ciencias experimentales & 2 y 8 \\
\hline Plantear y resolver problemas asociados con las ciencias a la vida cotidiana & $1,2,6$ y 8 \\
\hline Valorar las ciencias como un hecho cultural & $1,2,5$ y 8 \\
\hline $\begin{array}{l}\text { Reconocer la mutua influencia entre ciencia, sociedad y desarrollo tecnológico, así } \\
\text { como las conductas ciudadanas pertinentes, para procurar un futuro sostenible }\end{array}$ & $1,2,5$ y 8 \\
\hline $\begin{array}{l}\text { Conocer las orientaciones básicas de la Didáctica de Ciencias Experimentales para } \\
\text { adecuar las propuestas de enseñanza a la Educación Primaria y promover el desarrollo } \\
\text { personal de los estudiantes y la sostenibilidad del planeta Tierra, así como la igualdad } \\
\text { de género, la equidad y el respeto de los derechos humanos }\end{array}$ & 1,2 y 8 \\
\hline $\begin{array}{l}\text { Planificar propuestas de enseñanza innovadoras sobre contenidos de ciencias, } \\
\text { integradas en el área de Conocimiento del Medio, que promuevan el desarrollo del } \\
\text { pensamiento y conocimiento científico, de la actitud crítica y de la autonomía }\end{array}$ & $1,2,5,6$ y 8 \\
\hline
\end{tabular}

Fuente: Elaboración propia a partir de la Guía Docente del Grado en Educación Primaria, de conformidad con el Real Decreto 1393/2007.

Figura 3. Criterios del itinerario diseñado: currículo de educación primaria

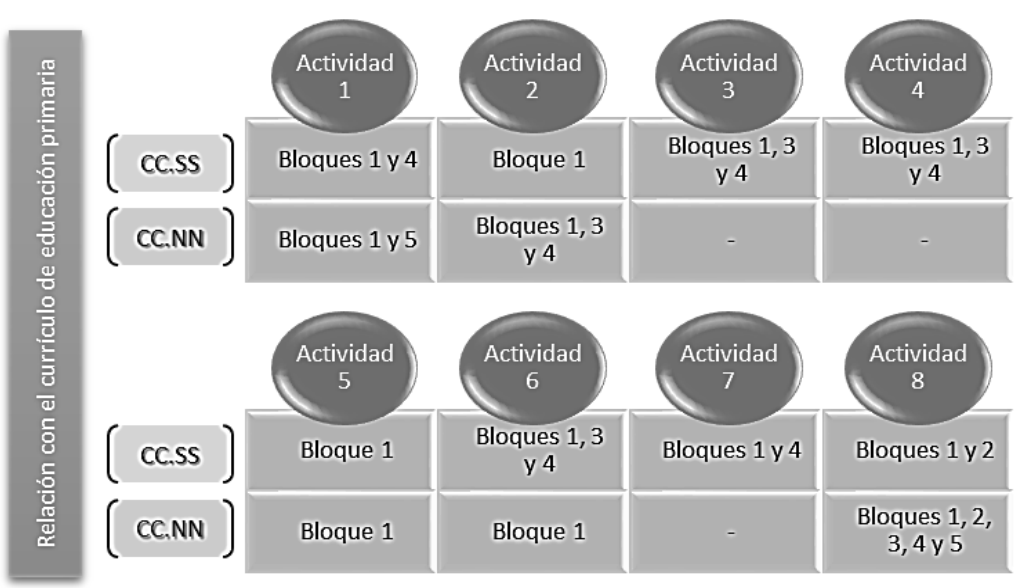

Fuente: Elaboración propia a partir de la Guía Docente del Grado en Educación Primaria, de conformidad con De conformidad con el RD 126/2014. 
Evaluación. Para conocer en qué grado se consiguen los objetivos de esta experiencia docente, junto a información cualitativa procedente de conversaciones con los estudiantes al final y durante el viaje e intercambio de impresiones continuo, se recurrió a un cuestionario -a cumplimentar por el alumnado unos días después de finalizada la actividad. El cuestionario fue diseñado mediante un Formulario de Google, de acceso abierto, y la url (https://goo.gl/forms/QksKjwPvsuO91GTH3) fue proporcionada al alumnado.

El cuestionario consta de 4 bloques de preguntas y cubre distintos ámbitos del itinerario y sus objetivos. El Bloque A es una validación o valoración logística y general del viaje; el bloque B, una evaluación didáctica del conjunto de actividades realizadas; el bloque C evalúa exclusivamente el análisis de geografía urbana; y el bloque $\mathrm{D}$ recoge los logros personales del conjunto del itinerario a modo de conclusiones.

Las preguntas del cuestionario tienen varios formatos: i) preguntas cerradas a responder conforme a una escala Likert de 1 a 5; ii) preguntas cerradas de opción múltiple (de respuesta única o compartida); y (iii) preguntas abiertas de respuesta breve.

Finalmente, las respuestas de los alumnos se homogeneizaron y normalizaron en una hoja de cálculo a través de una matriz de datos a los que se ha hecho un tratamiento estadístico básico de descriptores. Esto permite cuantificar y valorar el grado de consecución de los objetivos de la experiencia docente a través de un enfoque de tipo mixto (cuantitativo-cualitativo).

\section{Resultados}

\subsection{Validación del itinerario: percepción didáctica y logística}

La percepción general del itinerario que tienen los alumnos es realmente buena, así como la valoración que hacen sobre su logística; en una escala de 1 a 5, donde 5 es el valor máximo, califican el viaje con $4.5 \pm 0.7$ puntos (Figura 4). Destacan, por encima incluso de la media, su nivel de satisfacción, el profesorado responsable de las actividades y el compañerismo alcanzado entre ellos. Con menor nota, pero igualmente alta, puntúan la calidad de las actividades y la relación alojamiento/precio. Justo sobre la media sitúan los elementos didácticos tratados.

Figura 4. Valoración del alumnado sobre la logística y el viaje en su generalidad

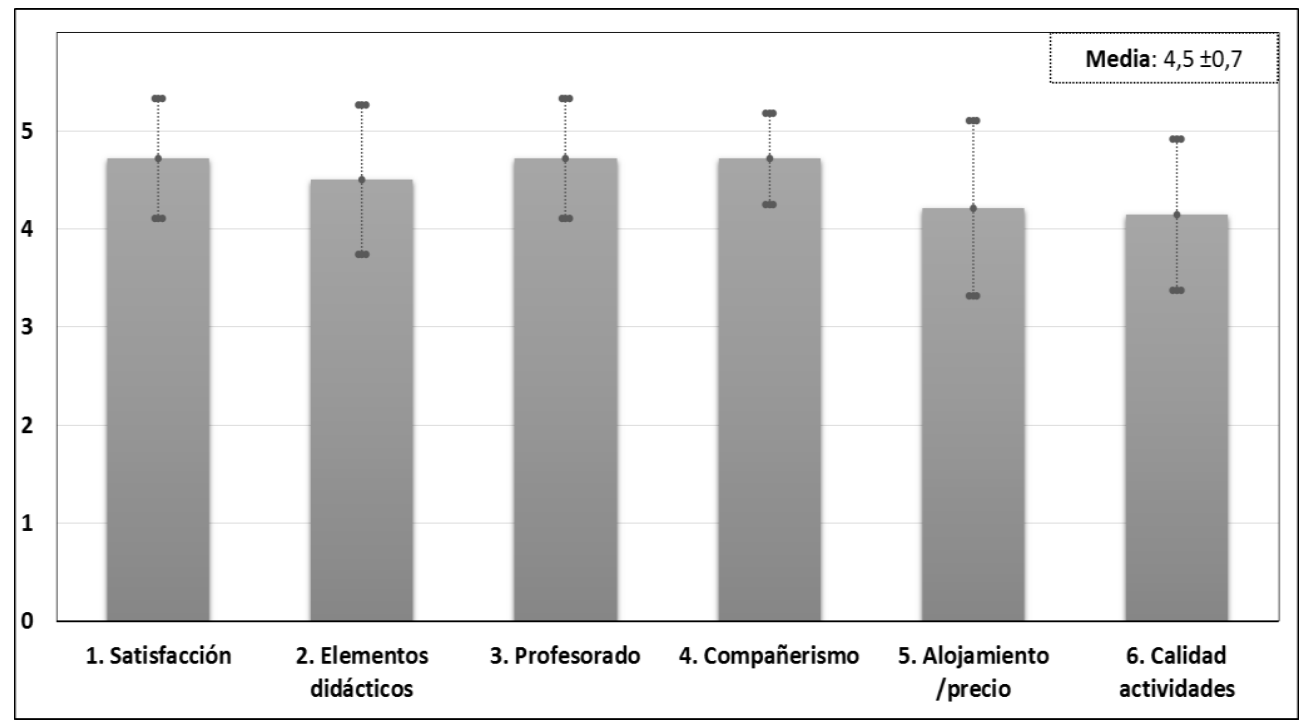

De forma cualitativa, los alumnos explican que están muy satisfechos con haber participado en el itinerario, en lo personal, social y académico, y son críticos con algunas de las actividades planteadas que consideran que no han conseguido despertar el mismo nivel de motivación que el resto, mayoritario. Un ejemplo es la 
visita a la Biblioteca Nacional, que había causado expectativas altas ante la idea de consultar y manejar fuentes primarias, tan mencionadas en clase, y sin embargo se limitó, por no estar disponibles las visitas guiadas por sus salas funcionales, a recorrer autónomamente el museo de la biblioteca, percibido como poco didáctico por el alumnado. Por este motivo, menos del $30 \%$ de los alumnos recomendaría su visita (Figura 5). El resto de actividades, en cambio, son recomendadas por entre el 50 y el 85\%.

Figura 5. Porcentaje de estudiantes que recomiendan las visitas y actividades realizadas

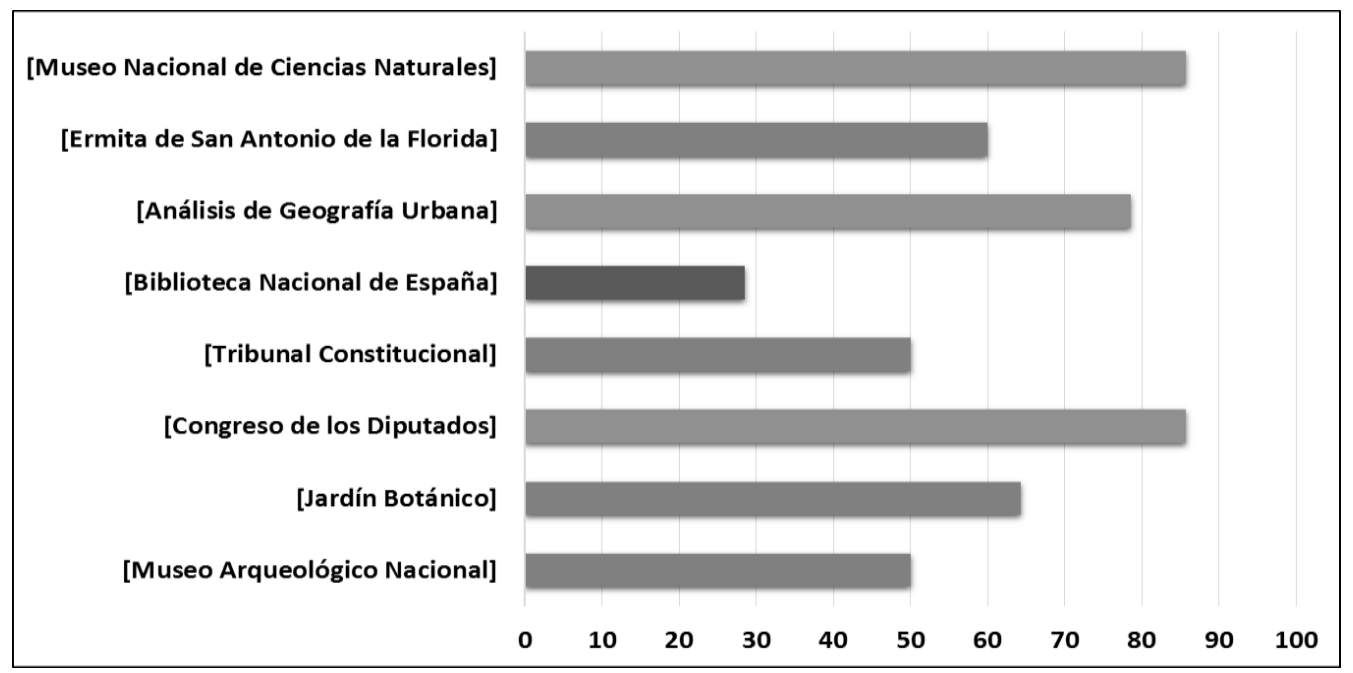

Al valorar de forma general las actividades (Figura 6), los alumnos son coherentes con el sentido de las recomendaciones anteriores y la Biblioteca Nacional (o, más rigurosamente, su museo) es la peor valorada, aunque consigue el aprobado (2.7 \pm 1.1 puntos); le sigue el Tribunal Constitucional (3.2 \pm 1.6$)$, un espacio valorado por los alumnos debido a su importancia, pero con el que no consiguieron empatizar por el tono conceptual y comunicativo de la visita, excesivamente técnico en el ámbito del Derecho y la política. A continuación, el Museo Arqueológico Nacional $(3.3 \pm 1.4)$ fue disfrutado pero, por su inmensidad, la falta de tiempo y la ausencia de objetivos concretos previamente marcados, no se optimizó la visita y causó cierto desapego. En el lado opuesto se sitúa el Museo Nacional de Ciencias Naturales (4.3 \pm 1.1 ), que se pudo visitar con tiempo y se optimizó su carácter marcadamente interactivo y espectacular. El análisis de geografía urbana también ha obtenido una calificación muy buena (4.2 \pm 1.0$)$, al ser una actividad novedosa, muy activa por parte del alumnado y con resultados inmediatamente palpables. El Congreso de los Diputados fue otra de las visitas que más se disfrutaron (4.0 \pm 1.2$)$, por las ganas de los alumnos de conocer en persona un lugar que no sienten ajeno por su mediatización. Con valoraciones intermedias, pero igualmente altas, encontramos: el uso del metro (3.6 \pm 1.1$)$, que para muchos alumnos fue un estreno y, por tanto, un aprendizaje; la Ermita de San Antonio de la Florida (3.7 \pm 1.5$)$, mejor valorada por los amantes de la historia del arte, impresionados por la presencia de Goya; y el Jardín Botánico (3.7 \pm 1.2$)$, cuyos invernaderos llamaron mucho la atención, así como la exposición de bonsáis, para muchos también un descubrimiento. 
Figura 6. Valoración general del alumnado sobre las visitas y actividades del itinerario

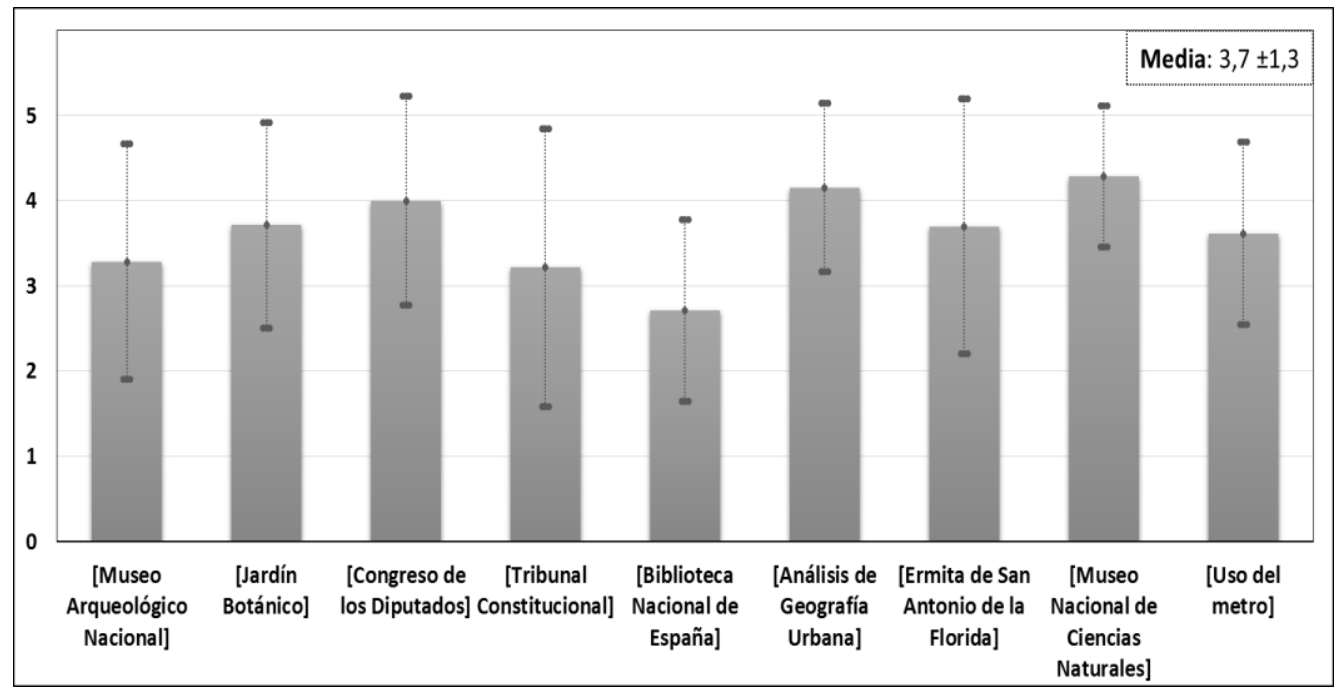

La valoración didáctica de cada actividad sigue el mismo signo (Figura 7), siendo destacable la conciencia pedagógica de los alumnos, que a pesar de valorar con notas intermedias las actividades que menos han disfrutado son capaces de reconocer su importancia didáctica y, en consecuencia, les suben la valoración. Esto es especialmente notable en los casos de la Biblioteca Nacional (+0.6) y el Tribunal Constitucional $(+0.2)$.

Figura 7. Valoración del alumnado sobre la calidad didáctica de las visitas y actividades del itinerario

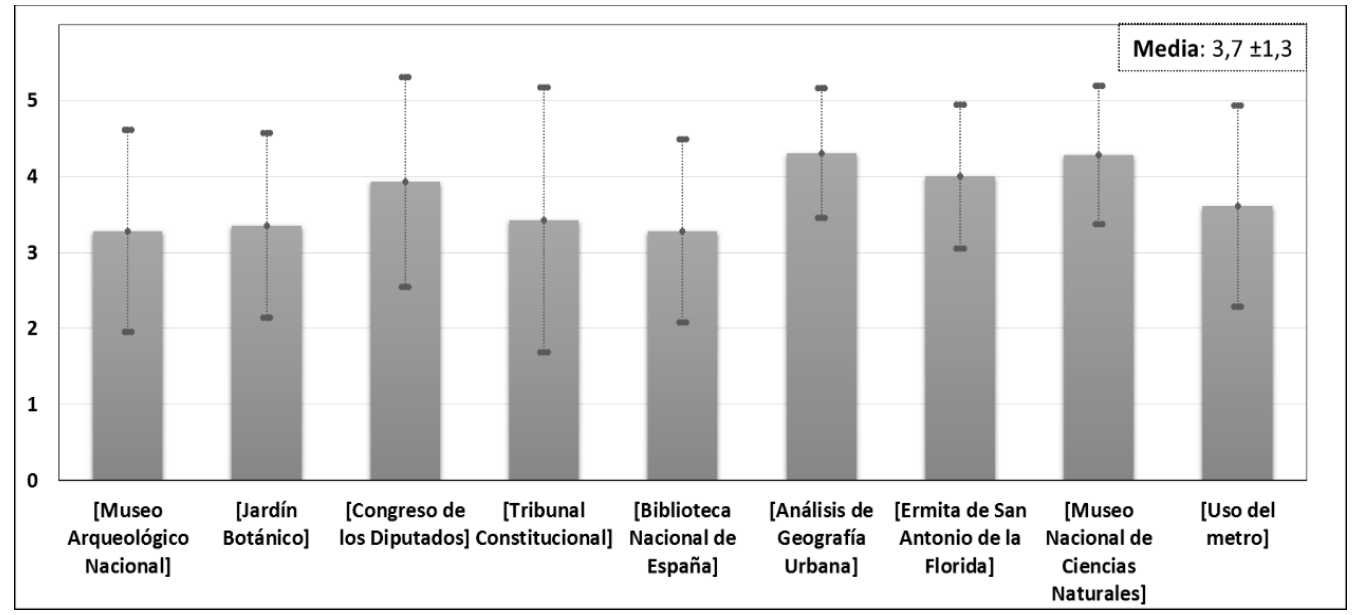

A raíz de estos resultados no cabe duda de que los maestros en formación, en términos de percepción didáctica y logística, validan el itinerario diseñado. El hecho de llevar a cabo una actividad fuera del aula suele ser muy atractivo para los estudiantes, de modo que presentan una gran disposición para disfrutar de las actividades que se proponen (Scheiner et al., 2019) y terminan siendo plenamente conscientes del aprovechamiento didáctico que conllevan (Chaparro et al., 2019).

\subsection{Resultados de aprendizaje, transferencia a la educación primaria y multidisciplinariedad}

Reconocidas las implicaciones didácticas del itinerario se hace necesario evaluar su eficacia, en relación con los nuevos conocimientos académicos adquiridos por los alumnos y el análisis de indicios de 
aprovechamiento didáctico de las visitas, lo que -en caso de ser positivos (Figura 8)- contribuye a validar el itinerario diseñado.

Figura 8. Respuestas normalizadas a las preguntas del cuestionario acerca de aprendizajes en las visitas y actividades del viaje

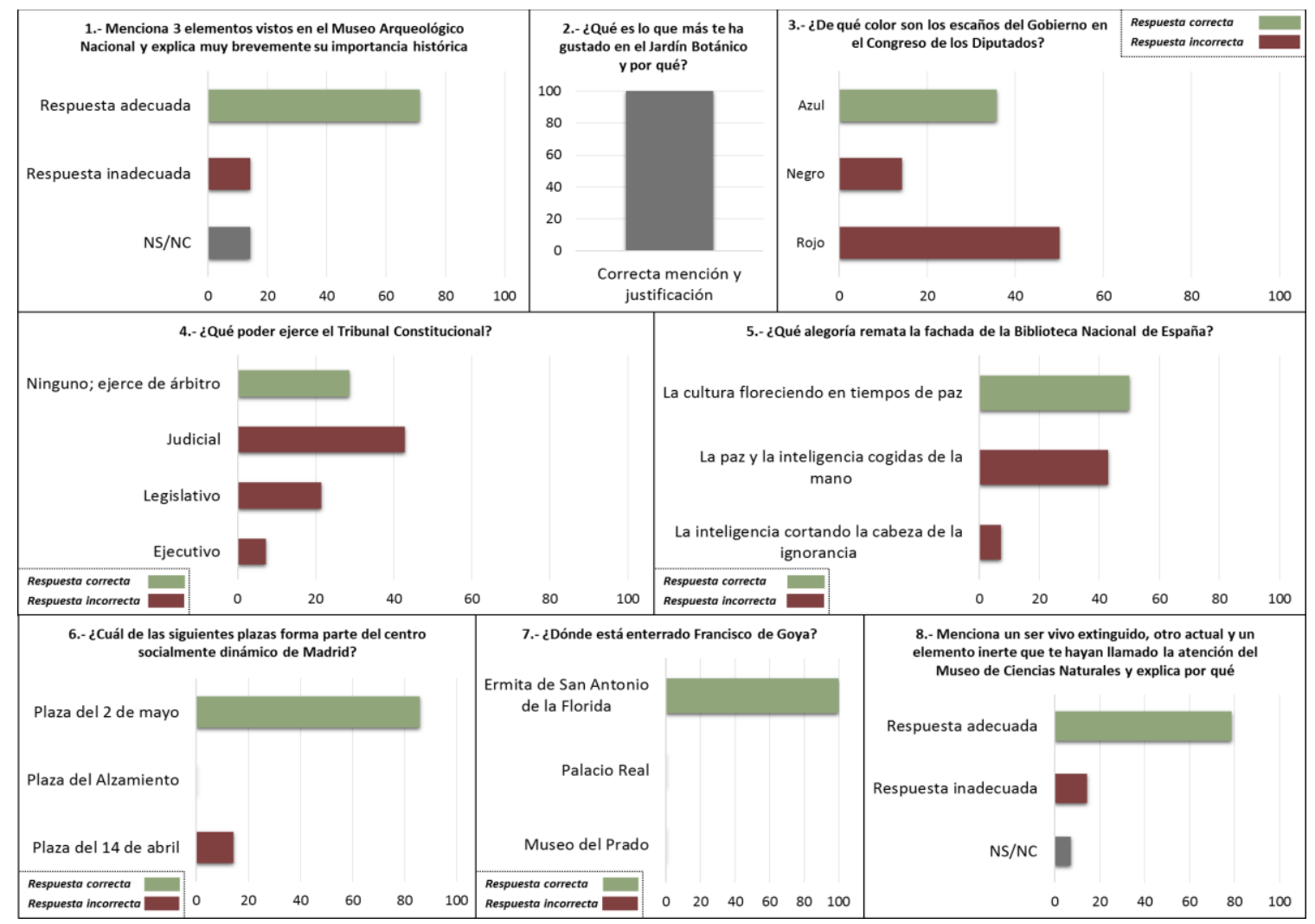

En este sentido, la visita al Museo Arqueológico Nacional fue didácticamente provechosa para el $70 \%$ de los alumnos, que son capaces de recordar objetos vistos y justificar su contexto e importancia. En el Jardín Botánico todos los alumnos saben mencionar y explicar elementos, por lo que se puede afirmar que la visita ha sido didácticamente útil. En el Congreso de los Diputados, en cambio, sólo el 35\% de los alumnos sabe responder a la pregunta sobre el color de los escaños del Gobierno, lo que demuestra que esta visita fue más actitudinal que conceptual, puesto que la emoción de conocer un lugar emblemático para ellos dejó en segundo plano la adquisición de aprendizajes más teóricos. En el Tribunal Constitucional los resultados son aún más pobres, ya que menos del 30\% del alumnado es capaz de expresar cuál es la función del organismo, lo cual denota la desatención producida ante la predicha falta de empatía hacia el ámbito jurídico y político. En la misma línea, por la falta de motivación en la visita, pero con mayor eficacia didáctica, sólo la mitad de los alumnos recuerda qué alegoría contiene la fachada de la Biblioteca Nacional. En cambio, la actividad de análisis de geografía urbana sí da sus frutos de forma palpable, seguramente por la mayor implicación del alumnado al abordarla, de forma que hasta el $86 \%$ puede señalar correctamente qué plaza de las propuestas forma parte del centro socialmente dinámico de Madrid. La visita que más eficacia didáctica alcanzó fue la de la Ermita de San Antonio de la Florida, la cual, probablemente por su pequeño tamaño y su exposición artística exclusiva, el $100 \%$ de los alumnos reconoce que alberga la tumba de Francisco de Goya. Finalmente, la visita al Museo Nacional de Ciencias Naturales fue también muy fructífera, al conseguir la motivación e implicación del alumnado, cautivado ante la espectacularidad de los objetos expuestos, de forma que casi el $80 \%$ es capaz de mencionar y explicar distintos tipos de seres presentes en el museo.

Los trabajos de campo apoyados en salidas o itinerarios han demostrado tener una amplia eficacia desde el punto de vista pedagógico, ya que permiten cubrir enfoques educativos desde la multidisciplinariedad. 
Guerrero (2009) lo defiende como "el aprendizaje que parte del contacto directo con la realidad, ampliando y profundizando los conocimientos, las destrezas y valores que se pueden adquirir al observar, descubrir e interpretar el sistema de interacción de cualquier fenómeno social" (p. 227). Se trata de cubrir contenidos curriculares que, como afirman Rodríguez et al. (2015), "el aula no permite (...) tienen como fin acercarse a los ambientes naturales para que estudiantes y maestros compartan en espacios que sean significativos y traigan consigo nuevas experiencias" (p. 124). Estas consideraciones coinciden con la discusión de nuestros resultados, que combinan el ámbito social y natural de forma secuenciada y simultánea, en una dinámica de aprendizaje didáctico claro.

Los itinerarios como recurso didáctico tienen una gran tradición en disciplinas geográficas, sobre todo en niveles de enseñanza no universitarios (Fernández, 2017; Molina, 2018; Sousa et al., 2016), pero también están apareciendo experiencias universitarias, con distintos enfoques en función de la disciplina. En titulaciones relacionadas con el turismo, por ejemplo, se asocian más a itinerarios-guía de aproximación profesional (Íñiguez et al., 2017; Rodríguez et al., 2015), mientras que en titulaciones territoriales mantienen una mayor vinculación geográfica (Tulla, 2010). Para titulaciones de formación docente la salida de campo es, como señalan Álvarez et al. (2016), una posibilidad. Tal como explican Pagés y Santisteban (2013), cuando los docentes toman conciencia de lo que están haciendo pueden actuar autónomamente en su aula y tomar las decisiones más pertinentes. Con nuestra actividad demostramos que el docente en formación adquiere esa toma de conciencia y así puede luego transmitir en sus clases de educación primaria, de una forma más significativa y asimilada, todo lo aprendido (Garello y Rinaudo, 2013), con una transferencia curricular apuntada previamente en la Figura 3.

\subsection{Aprovechamiento del análisis de geografía urbana}

El resultado más claramente visible del recorrido urbano, relacionado con el currículo universitario y también de la educación primaria, es la adquisición de la competencia geográfica de la orientación, por parte de todos los alumnos, al ser capaces de seguir el itinerario marcado por la actividad (Figura 9). Aunque llama la atención que la mayoría prefieren utilizar una aplicación móvil de geolocalización en lugar del mapa, todos consiguen completar el recorrido de modo correcto. Cuando se llevan a cabo experiencias de itinerarios o salidas didácticas es muy habitual que se consigan desarrollar competencias cartográficas (Fernández, 2017).

Figura 9. Recorrido de la actividad a través de los barrios de Malasaña y Chueca en el centro de Madrid

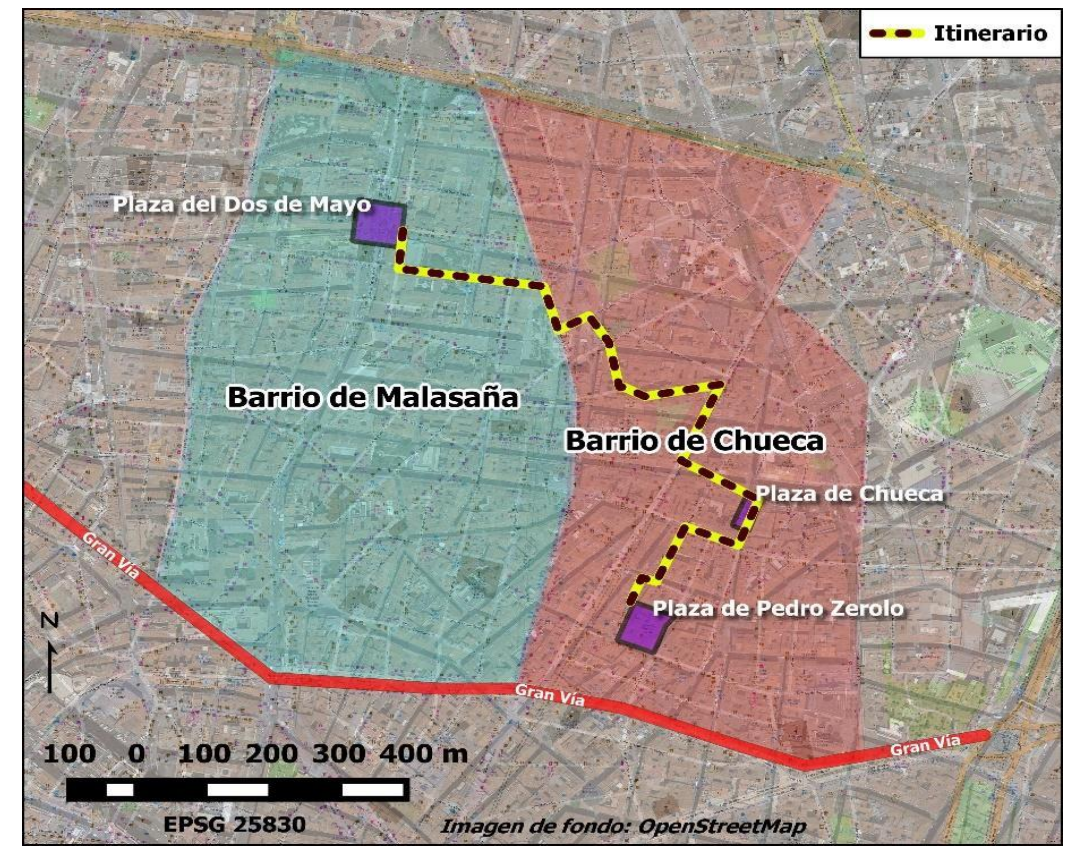


Otra competencia geográfica desarrollada es la observación de la realidad, con mirada consciente y crítica. Al no estar muy familiarizados con estos procedimientos técnicos de observación y representación, los estudiantes asumen la actividad con entusiasmo. De hecho, al preguntárseles si estas técnicas geográficas les han ayudado a comprender y realizar el análisis de geografía urbana solicitado, hasta un $93 \%$ de los alumnos responde positivamente (Figura 10).

No obstante, se reconoce una técnica que no han sabido desarrollar mayoritariamente: la interacción social. Sólo un $21 \%$ de los alumnos reconoce haber tenido que interactuar con viandantes para resolver mejor el ejercicio, así como que el resultado fue satisfactorio (Figura 10). La mayoría de los alumnos no se ha atrevido a hacer preguntas, no sólo por timidez y falta de confianza sino porque no han sido conscientes de la importancia de esta técnica de análisis. Es un aspecto en el que hay que insistir en futuras ocasiones.

La mayoría de los alumnos no reconoce ninguna dificultad a la hora de realizar la actividad, y el escaso 29\% que menciona dificultades lo hace sólo referidas a la orientación geográfica y al arte de dibujar el mapa (Figura 10). Se ha conseguido que asuman la importancia de trabajar con mapas y de recurrir a una observación sistemática.

Los alumnos son conscientes de los nuevos aprendizajes, hasta el punto en que el $85 \%$ reconoce haber aprendido competencias y contenidos geográficos nuevos (Figura 10); el resto afirmó saberlos previamente. Todos, por tanto, han movilizado técnicas de investigación que, a pesar de ser básicas, no conocían o apenas habían usado, por lo que suponemos que a partir de ahora las incorporarán a su acervo universitario. Otras experiencias de trabajos de campo con estudiantes también han demostrado que esta estrategia consigue en el alumnado un aprendizaje consciente (Jiménez et al., 2019; Rodríguez et al., 2015).

Los estudiantes comparten la importancia de estos nuevos aprendizajes, especialmente útiles en futuros docentes. El 100\% afirma que la actividad le ha parecido interesante para aplicar en el ámbito educativo (Figura 10). No sólo es una experiencia útil desde el punto de vista científico sino también didáctico. Esta transferencia educativa es frecuente en métodos didácticos fuera del aula (Sánchez, 2018; Valverde et al., 2018).

Figura 10. Respuestas normalizadas de la percepción didáctica de los análisis de geografía urbana

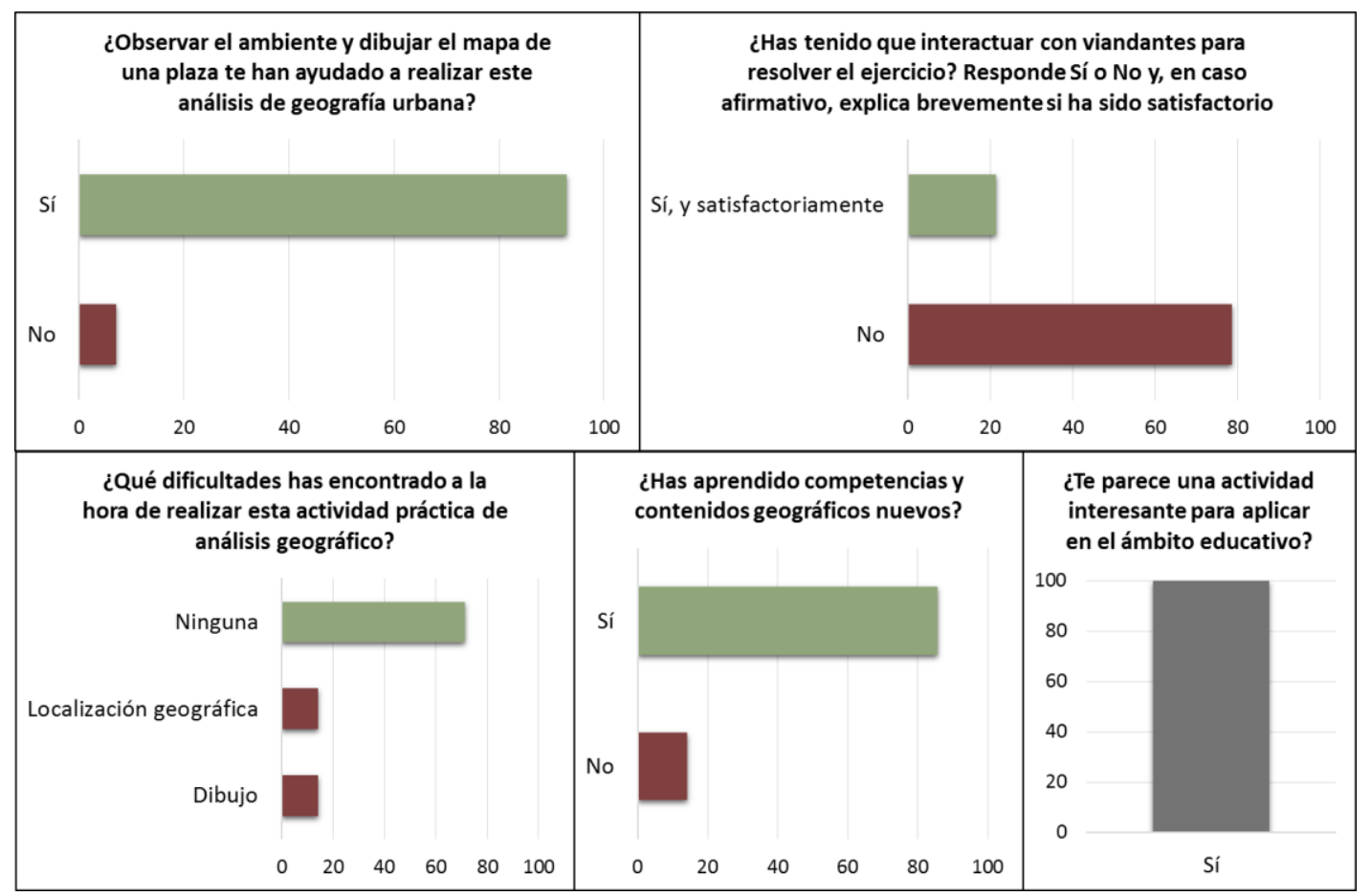


En cuanto a la calidad de sus análisis urbanos, en relación con las transformaciones del uso del espacio inducidas por el turismo en barrios céntricos, es ciertamente buena. Menos un caso, todos son capaces de mencionar algún barrio céntrico que presenta un gran dinamismo socioeconómico en la actualidad, y más de la mitad completa con un segundo barrio (Figura 11).

De nuevo todos los alumnos, salvo uno, son capaces de descifrar cuál es la principal caracterización de la estructura urbana: la presencia predominante de locales comerciales y de restauración (tiendas y bares) (Figura 11). Es muy importante que entiendan esta circunstancia porque demuestra que han dado con la clave de las transformaciones del espacio que están analizando.

Se confirma esta idea entre casi el $80 \%$ de los alumnos, que sabe discernir cuáles son los principales efectos de las intensas dinámicas sociales y económicas: subida de precios y expulsión de residentes (Figura 11). Este es el conflicto propiamente dicho (Cócola, 2015), y entenderlo supone haber aprendido cómo funcionan los procesos de gentrificación turística.

Figura 11. Respuestas normalizadas del aprovechamiento didáctico de los análisis de geografía urbana

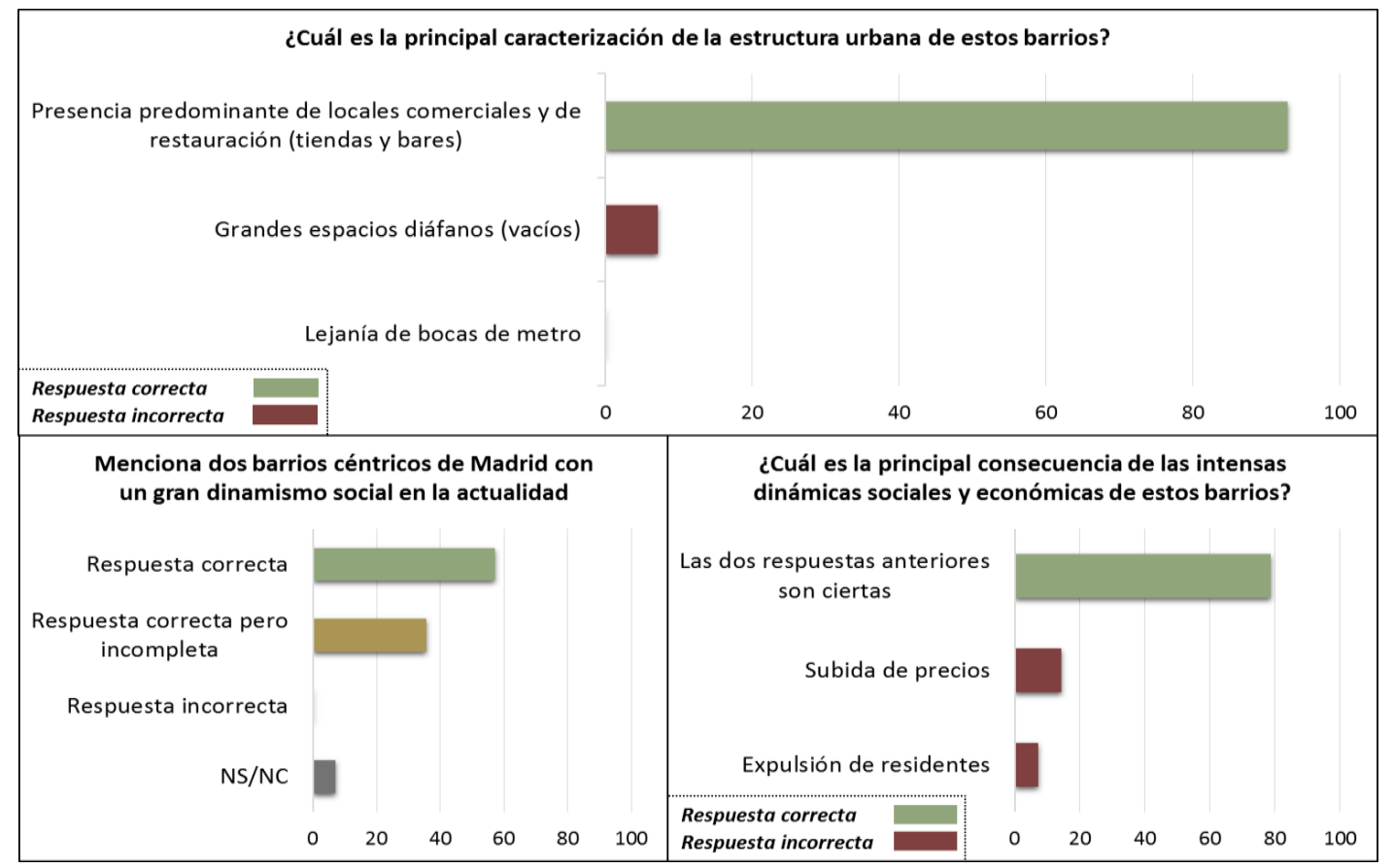

Para seguir desarrollando competencias geográficas, concretamente aprender a observar y representar los impactos físicos y sociales de la intensificación del uso turístico del espacio, se indujo a los alumnos a reproducir en mapas las estructuras y dinámicas observables a escala de las plazas de estudio, ofreciéndoles previamente unas instrucciones conceptuales.

Las respuestas que han dado en el cuestionario y el mapa que los propios alumnos han dibujado de su plaza de estudio atestiguan que la actividad se ha desarrollado adecuadamente. La cartografía activa es un buen método para la comprensión de fenómenos espaciales (Sousa et al., 2016). Tomando de ejemplo uno de los mapas por su mayor calidad visual (Figura 12) pero apreciable en todos, podemos observar perfectamente la mayoría de los elementos mencionados, recurriendo para ello a técnicas cartográficas básicas como la simbolización, en forma, color, tramas, etc., tal como se les indicó, aunque todos han olvidado señalizar la orientación del mapa. La estructura urbana que han reconocido se aprecia en los objetos que representan: la estatua del centro de la plaza, todos los bancos que hay alrededor, las zonas de parque infantil, el área de venta ambulante y el colegio. Aunque sólo representaran este establecimiento, en la puesta en común posterior reconocieron el resto, no destacados antes por ser todos iguales: bares con terrazas. Otros grupos sí los mencionaron, dándoles la importancia que merecen a la 
hora de explicar las dinámicas sociales. La gran mayoría de los alumnos -tal como se constató en la puesta en común-supo ver y comprender las dinámicas del fenómeno urbano efecto del uso turístico del espacio público en las grandes ciudades, comprobando de primera mano cómo la función residencial y los establecimientos convencionales asociados habían quedado relegados a un claro segundo plano.

Figura 12. Ejemplo de representación gráfica (derecha) y aspecto real (izquierda) de la Plaza 2 de Mayo de Madrid

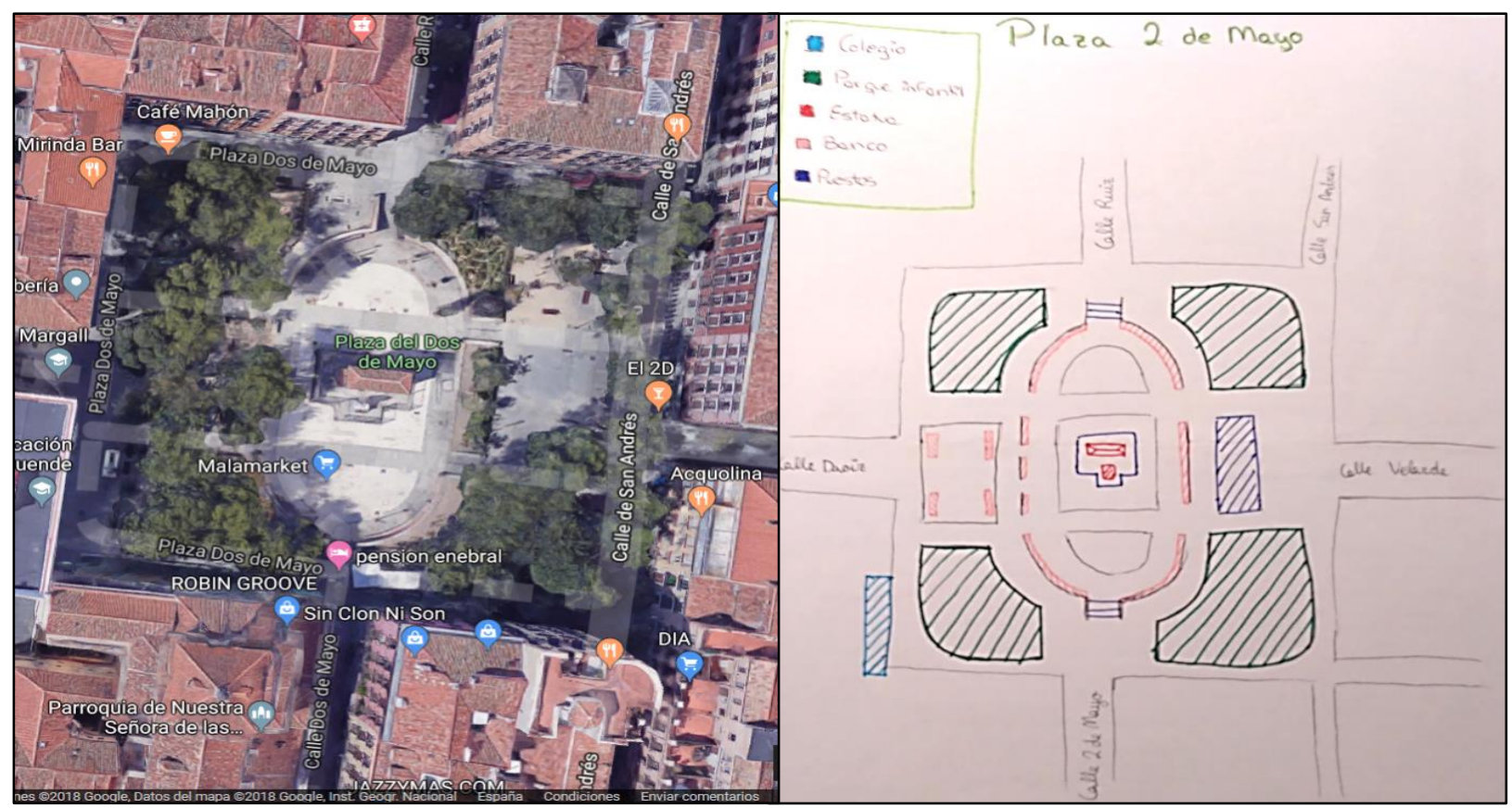

Fuente: Google Maps.

Para esta puesta en común se observó el papel trascendental que habían adoptado las herramientas geográficas puestas a disposición del alumnado. El aprendizaje no fue sólo conceptual sino también procedimental. Asimismo, a la hora de interactuar con un espacio ajeno al alumnado y reflexionar sobre un fenómeno complejo como es el de los efectos de la intensificación del uso turístico del espacio, se efectuó un aprendizaje actitudinal. Como señalan Gómez et al. (2017), es importante que los métodos didácticos lleven a que el alumnado "descubra y se identifique con el medio (...) atendiendo a la complejidad de los hechos sociales en todo su significado y matices" (p. 224).

En definitiva, se consiguió, además de un aprovechamiento pedagógico y didáctico, un adecuado fomento de distintas competencias, tanto universitarias como las llamadas "clave" en la etapa primaria. De las que establece la LOMCE, la actual ley educativa española (Ley Orgánica 8, 2013), desarrolladas en el RD 126/2014 (p. 19 352), las más claramente abordadas son: 1a.) Comunicación lingüística, 3a.) Competencia digital, 4a.) Aprender a aprender, 5a.) Competencias sociales y cívicas, (6a.) Sentido de iniciativa y espíritu emprendedor y 7a.) Conciencia y expresiones culturales. Este punto es importante por la gran ayuda que supondrán estos aprendizajes en el futuro docente a la hora de ejercer su profesión, focalizada, en última instancia y en función del paradigma pedagógico actual, en el desarrollo de las competencias clave de los alumnos (Ion y Cano, 2012). Las respuestas al cuestionario y los mapas atestiguan que se han conseguido aprendizajes multidisciplinares y se han abordado distintas competencias.

\subsection{Desarrollo personal}

Un itinerario didáctico no sólo busca aprendizaje académico, ya sea conceptual o procedimental, sino también, y aquí está la clave de su identidad, ofrecer la vivencia de una serie de experiencias personales, sociales y culturales que en la quietud individual no se encuentran disponibles. De este modo, al término del mismo se preguntó a los alumnos por una serie de inputs que se prevé se logran en salidas de estudio. 
En una escala Likert de 1 a 5, donde 5 es el valor máximo, los alumnos evaluaron los inputs con una media sobresaliente: $4.5 \pm 0.7$ puntos (Figura 13). Así pues, podemos afirmar que el aprovechamiento del itinerario no sólo ha sido didáctico sino, también, de desarrollo personal, en la línea de lo que más autores han concluido de otras experiencias fuera del aula (Benejam, 2003; Costillo et al., 2014; Crespo et al., 2018).

Figura 13. Valoración del alumnado de sus logros personales durante el viaje

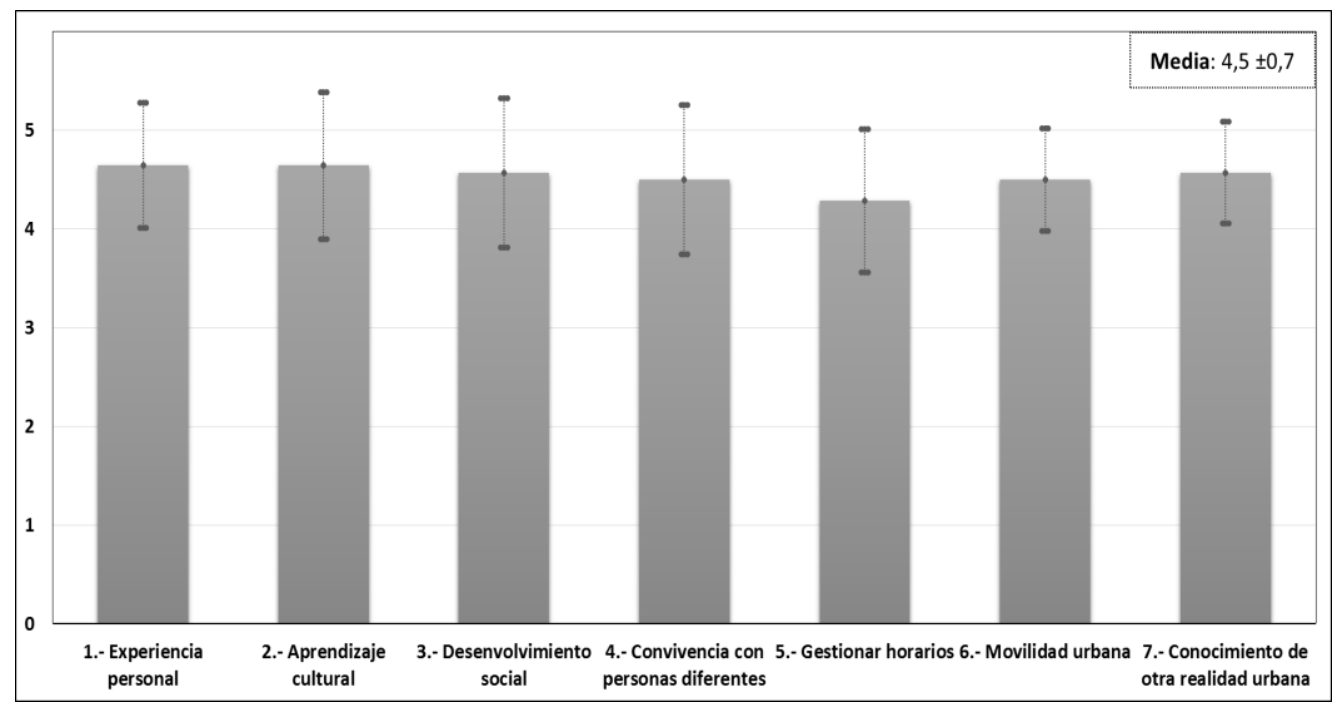

\section{Conclusiones}

Para valorar en qué medida se han conseguido los objetivos del itinerario ha sido fundamental haber hecho un seguimiento personal de su desarrollo y poder recurrir a la evaluación cuantitativa de un cuestionario resuelto por los alumnos.

El diseño del itinerario didáctico ha quedado ampliamente validado según la experiencia con los maestros en formación. Los contenidos y las destrezas adquiridas en el Museo Arqueológico Nacional, Jardín Botánico, Ermita de San Antonio de la Florida, Museo de Ciencias Naturales y el análisis de geografía urbana han sido mayoritariamente evidentes. En el Congreso de los Diputados, Tribunal Constitucional y Biblioteca Nacional, en cambio, no se ha conseguido un aprendizaje memorístico, pero sí un aprendizaje cualitativo, muy notable en el acompañamiento del alumnado por parte de los profesores.

Desde un punto de vista didáctico, el itinerario ha supuesto la adquisición y consolidación de conocimientos de Ciencias Sociales -tanto de su didáctica como de su transferencia a la educación primaria-basados sobre todo en la historia, organización territorial, fuentes, geografía urbana, movilidad, convivencia, cartografía, valorización patrimonial. Por parte de las Ciencias Naturales y Experimentales (y su didáctica), se ha aprendido especialmente sobre la iniciación a la investigación científica, la caracterización y diversidad de los seres vivos y de forma genérica el uso de la tecnología y objetos como elemento desarrollador de la sociedad. A un nivel general, los logros adquiridos están más relacionados con el crecimiento personal, el desenvolvimiento social, la responsabilidad del trabajo en grupo, etc. En definitiva, el aprovechamiento del itinerario puede concebirse desde una doble dimensión: didáctico-pedagógica por un lado, con una vertiente continuamente multidisciplinar, y competencial-vivencial por otro, gracias a la ruptura de la rigidez social de las paredes del aula.

Por otra parte, los aspectos a mejorar se concentran en dos sentidos: por un lado, conseguir mayor motivación a la hora de visitar lugares que, a priori, los estudiantes pueden percibir menos interesantes; $y$, por otro lado, no saturar al alumnado con una frecuencia demasiado alta de actividades por día. La motivación está muy relacionada con la significación discente, así que probablemente habría sido necesario trabajar previamente la visita a los lugares de aprendizaje más densos, como la Biblioteca Nacional o el 
Tribunal Constitucional, con herramientas como la preparación de fichas didácticas para concentrar la atención en las visitas. Del mismo modo, un exceso de actividades, lejos de mejorarlo, puede enturbiar el aprendizaje, por agotamiento ante la continuidad sin apenas descanso de procesos cognitivos. No es casualidad que algo más de la mitad de los participantes en el viaje hayan expresado su preferencia por más tiempo libre.

El análisis de geografía urbana quizá sea la actividad que mejores resultados ha conseguido, en línea con el mayor esfuerzo que requería del alumnado y la mayor preparación que se hizo de la misma, por constituir, en el conjunto del itinerario, la mejor oportunidad de desarrollar, de forma activa y no pasiva como en el resto de visitas, no sólo un aprendizaje teórico sino también, y de forma muy amena y significativa, habilidades geográficas básicas para las Ciencias Sociales y las Ciencias Naturales e, incluso, contenidos actitudinales. A raíz de los resultados obtenidos, creemos que el turismo y la geografía urbana deben tener más presencia curricular y que actividades de trabajo de campo como esta son un buen procedimiento para acercar la temática a los docentes en formación y que luego estos sean capaces de trasladarla a sus futuros alumnos.

Existen muchas formas de enfocar un viaje de estudios en una titulación universitaria. Para el Grado en Educación Primaria, nuestra propuesta es convertirlo en un itinerario didáctico mediante el diseño de una serie de visitas con un alto contenido didáctico para que, al desarrollo de las habilidades y actitudes convencionales que se les presupone a los viajes con estudiantes, se les sume una rigurosa y planificada adquisición de contenidos didácticos y la canalización de lo extraacadémico hacia logros personales con buena valoración en la profesión docente futura del alumnado. A la vista de los resultados, la finalidad parece haberse cumplido en el caso de esta experiencia.

\section{Referencias}

Agencia Nacional de Evaluación de la Calidad y Acreditación (2018). Memoria verificada del título de Grado en Educación Primaria. Universidad de Murcia.

https://www.um.es/documents/299436/319114/grado ed primaria modificado aleman.pdf/5a8c3e40$\underline{\text { b907-41d1-952f-cfba891215b5 }}$

Aguilera, D. (2018). La salida de campo como recurso didáctico para enseñar ciencias. Una revisión sistemática. Revista Eureka sobre Enseñanza y Divulgación de las Ciencias, 15(3).

https://doi.org/10.25267/Rev Eureka ensen divulg cienc.2018.v15.i3.3103

Álvarez, D., Vásquez, W. y Rodríguez, L. (2016). La salida de campo, una posibilidad en la formación inicial docente. Didáctica de las Ciencias Experimentales y Sociales, 31, 61-77.

https://doi.org/10.7203/dces.31.8431

Benejam, P. (2003). Los objetivos de las salidas. Iber: Didáctica de las Ciencias Sociales, Geografía e Historia, (36), 7-12.

Cañas, A. y Martín-Díaz, M. (2010). ¿Puede la competencia científica acercar la ciencia a los intereses del alumnado? Alambique, 66, 80-87.

Chaparro, A., Martínez, C., Robles, F., Cespedosa, R. (2019). Desarrollar la conciencia histórica a través del patrimonio en el grado en educación primaria. Didáctica de las Ciencias Experimentales y Sociales, (36), 1732. https://doi.org/10.7203/dces.36.12672

Cócola, A. (agosto, 2015). Tourism and commercial gentrification. En RC21 International Conference on The Ideal City: between myth and reality. Representations, policies, contradictions and challenges for tomorrow's urban life. Urbino (Italia). https://www.rc21.org/en/wp-content/uploads/2014/12/E4C\%C3\%B3cola-Gant.pdf 
Costillo, E., Borrachero, A., Esteban, R. y Sánchez-Martín, J. (2014). Aportaciones de las salidas al medio natural como actividades de enseñanza y de aprendizaje según profesores en formación. Indagatio didáctica, 6(3), 10-22. https://doi.org/10.34624/id.v6i3.3983

Council for Learning Outside the Classroom (2006). Learning outside the classroom. Manifesto. DfES Publications.

Crespo, J., Gómez, M. y Cruz, L. (2018). Una aproximación a los parques nacionales y sus paisajes a través de itinerarios didácticos. Espacio, Tiempo y Forma, (11), 121-140.

https://doi.org/10.5944/etfvi.11.2018.22359

del Toro, R. y Morcillo, J. (2011). Las actividades de campo en educación secundaria. Un estudio comparativo entre Dinamarca y España. Enseñanza de las Ciencias de la Tierra, 19(1), 39-47. https://www.raco.cat/index.php/ECT/article/view/244377

Delgado, A. y de Justo, E. (2018). Evaluación del diseño, proceso y resultados de una asignatura técnica con aprendizaje basado en problemas. Educación XX1, 21(2), 179-203. https://doi.org/10.5944/educxx1.19415

Fernández, J. (2017). La salida de campo como recurso didáctico para conocer el espacio geográfico: el caso de la ciudad de Valladolid y Soria. Didáctica geográfica, (18), 91-109. http://didacticageografica.agegeografia.es//index.php/didacticageografica/article/view/384

Garello, M. y Rinaudo, M. (2013). Autorregulación del aprendizaje, feedback y transferencia de conocimiento. Investigación de diseño con estudiantes universitarios. Revista Electrónica de Investigación Educativa, 15(2), 131-147. https://redie.uabc.mx/redie/article/view/451/618

Gómez, C. J., Miralles, P., López, R. y Prats, J. (2017). Las competencias históricas en el horizonte. Propuestas presentes y perspectivas de futuro. En R. López, P. Miralles y J. Prats (Eds.), Enseñanza de la historia y competencias educativas (pp. 215-227). Graó.

Guerrero, M. (2009). Las salidas de campo como instrumento de aprendizaje. Dialéctica Libertadora, 2, 225239.

Íñiguez, L., íñiguez, T. y Melero, I. (2017). Un análisis de las salidas de campo autogestionadas con el Grado en Turismo tras tres años de experiencia. CLIO. History and History teaching, (43), 242-250.

http://clio.rediris.es/n43/articulos/IniquezMelero2017.pdf

Ion, G. y Cano, E. (2012). La formación del profesorado universitario para la implementación de la evaluación por competencias. Educación XX1, 15(2), 249-270. https://doi.org/10.5944/educxx1.15.2.141

Jiménez, L., Vega, N., Capa, E., Fierro, N. y Quichimbo, P. (2019). Estilos y estrategias de enseñanzaaprendizaje de estudiantes universitarios de la ciencia del suelo. Revista Electrónica de Investigación Educativa, 21, e04, 1-10. https://doi.org/10.24320/redie.2019.21.e04.1935

Ley Orgánica 8/2013, de 9 de diciembre, para la mejora de la calidad educativa (LOMCE). (2013). Boletín Oficial del Estado, 295, 10 de diciembre de 2013. https://www.boe.es/eli/es/lo/2013/12/09/8

Molina, M. P. (2018). La educación patrimonial en la didáctica de las ciencias sociales en primaria. Contextos Educativos, (22), 199-213. https://doi.org/10.18172/con.3087

Pagés, J. y Santisteban, A. (2013). Una mirada del pasado al futuro en la didáctica de las Ciencias Sociales. En J. Pagés y A. Santisteban (Eds.), Una mirada al pasado y un proyecto de futuro. Investigación e innovación en didáctica de las ciencias sociales (pp. 17-39). Universitat Autònoma de Barcelona.

Pedrinaci, E. (2012). Trabajo de campo y aprendizaje de las ciencias. Alambique, 71, 81-89. 
Real Decreto 1393/2007, de 29 de octubre, por el que se establece la ordenación de las Enseñanzas Universitarias Oficiales. (2007). Boletín Oficial del Estado, 182, 30 de octubre de 2007.

https://www.boe.es/eli/es/rd/2007/10/29/1393/con

Real Decreto 126/2014, de 28 de febrero, por el que se establece el currículo básico de la Educación Primaria. (2014). Boletín Oficial del Estado, 52, 1 de marzo de 2014.

https://www.boe.es/eli/es/rd/2014/02/28/126

Rebelo, D., Marqués, L. y Costa, N. (2011). Actividades en ambientes exteriores al aula en la Educación en Ciencias: contribuciones para su operatividad. Enseñanza de las Ciencias de la Tierra, 19(1), 15-25.

Rodríguez, A., Díaz, E. y Carreño, J. (2015). Turismo como agente educativo: Un análisis desde las salidas de campo. Turismo y Sociedad, 16, 117-130. https://doi.org/10.18601/01207555.n16.08

Sánchez, J. L. (2018). Salida de campo por el valle del Henares y su canal de riego. Tarbiya, Revista de Investigación e Innovación Educativa, (46), 55-72. https://doi.org/10.15366/tarbiya2018.46.04

Scheiner, J., Huber, O. y Lohmüller, S. (2019). Children's mode choice for trips to primary school: a case study in German suburbia. Travel Behaviour and Society, 15, 15-27.

https://doi.org/10.1016/j.tbs.2018.09.006

Sequera, J. y Janoshka, M. (2015). Gentrification dispositifs in the historic centre of Madrid: a reconsideration of an urban governamentality and state-led urban gentrification. En L. Lees, H. Shin, E. \& López-Morales (Eds.), Global gentrifications: uneven development and displacement (p. 375-394). Polity Press.

Solbes, J. (2011). ¿Por qué disminuye el alumnado de ciencias? Alambique, 67, 53-61.

Sorrentino, A. y Bell, P. (1970). A comparison of attributed values with empirically determined values of secondary school science field trips. Science Education, 54(3), 233-236.

https://doi.org/10.1002/sce.3730540308

Sousa, S., García, D. y Souto, X. (2016). Educación geográfica y las salidas de campo como estrategia didáctica: un estudio comparativo desde el Geoforo Iberoamericano. Biblio3W, Revista Bibliográfica de Geografia y Ciencias Sociales, 21(1.155), 1-22. http://www.ub.edu/geocrit/b3w-1155.pdf

Tulla, A. (2010). Los nuevos planes de estudio de los títulos de grado en Geografía adaptados al modelo del Espacio Europeo de Educación Superior (EEES). Estudios Geográficos, 71(268), 319-338.

http://estudiosgeograficos.revistas.csic.es/index.php/estudiosgeograficos/article/view/312/312

Valverde, F., Ramírez, A., Mora, M., López, J.A., Medina, S. y Arrebola, J. C. (2018). Itinerarios interdisciplinares en el Grado de Educación Primaria. Revista de Innovación y Buenas Prácticas Docentes, (6), 69-75. https://www.uco.es/ucopress/ojs/index.php/ripadoc/article/view/11080 